\title{
EDITORIAL
}

\section{HUMBERTO MATURANA Y EL SENTIDO DE LO HUMANO}

\author{
Víctor Rey Riquelme \\ Máster en Comunicación Social \\ Director del Servicio de Estudios de la Realidad \\ Santiago de Chile \\ victorrey@hotmail.com
}

En el último curso del Servicio de Estudios de la Realidad (SER) uno de los autores y textos que más nos cuestionó y nos hizo reflexionar fue el libro del biólogo y filósofo chileno Humberto Maturana, El Sentido de lo Humano. Su pensamiento es muy original y sus aportes dan luces a todas las áreas de la vida. Este autor es uno de los que más nos ayuda en este tiempo de tantas preguntas ante un mundo nuevo. Recuerdo con alegría los momentos de conversación con los alumnos y el entusiasmo que nos generaba cada párrafo de su libro. Comparto aquí algunos de los conceptos que logramos descifrar y discernir juntos y que consideramos de vital utilidad.

\section{La teoría biológica del conocer}

El aporte de Humberto Maturana a la nueva propuesta epistemológica es fundamental. Es el primer científico que desde su hacer de biólogo propone que el conocimiento es un fenómeno biológico y que, por tanto, sólo puede ser estudiado y conocido como tal. Aún más, su proposición es que la vida misma se entiende como un proceso de conocimiento, el cual le sirve al organismo para adaptarse, para sobrevivir. Ningún organismo está interesado en saber si su conocimiento es verdadero o no, cuando eso no importa para su supervivencia. Así la obra de Maturana puede ser caracterizada como un sistema explicativo unitario y ontológico de la vida o de la vivencia. Ontológico, porque ve la experiencia humana desde un punto de vista situado dentro de ella misma y no desde un punto de vista externo o fuera de ella. 


\section{El determinismo estructural}

Maturana postula, también, que todos los cambios que puedan experimentar los sistemas autopoiéticos son determinados por su propia organización y estructura. Aunque estos dos conceptos son propiedades de los seres vivos -entendidos en la terminología de Maturana como "unidades compuestas de una clase particular"-, no son sinónimos. La organización

se refiere a la relación que se da entre los componentes de una "unidad compuesta" y que determina las propiedades de esa unidad. La estructura, en cambio, apunta a los componentes. Actuales y a la relación que ellos deben satisfacer al participar en la constitución de una "unidad compuesta". En otros términos, los seres vivos mantenemos nuestra organización durante toda la vida; precisamente, el que nos reconozcamos siempre la misma persona, desde nuestra infancia a nuestra vejez, está en relación a que nuestra organización ha permanecido invariante. Pero la estructura es variable: determina qué cambios son posibles para una "unidad compuesta" y que interacciones específicas se requieren para desencadenar esos cambios.

Así, si todo un sistema está operacionalmente constituido por su organización, su operación efectiva es realizada en -y a través de- su estructura, de modo tal que, aunque el dominio (o espacio) de interacciones del sistema como totalidad está especificado por su organización, las interacciones efectivas ocurren a través de sus componentes. A la luz de esto, el afirmar que los sistemas son estructuralmente determinados implica que todo lo que en ellos ocurre no está determinado por nada externo a ellos; y que cuando, como observadores, vemos algo que incide sobre un sistema, no es ese algo lo que provoca el cambio, sino solo lo que desencadena dentro del sistema un cambio estructural que estaba previamente determinado en la configuración del mismo.

\section{El cierre organizacional y la autorreferencialidad}

El cierre organizacional está referido al hecho de que, definida la característica de la unidad del sistema vivo, está en su capacidad de mantener su integridad. Maturana plantea que la "línea de fondo" es mantener nuestro estatus como tales, que es permanecer vivos. La adaptación, entonces, requiere de cambios estructurales en la unidad de los seres vivos y debido a que ellos son determinados estructuralmente y organizacionalmente cerrados, los sistemas vivos son autónomos en el sentido que sobreviven, prosperan o peligran bajo sus propias leyes de su quehacer. La organización del sistema vivo es circular, autorreferencial, recursiva y su organización es una organización cerrada y, por lo tanto, autónoma. 


\section{El Multiverso}

$\mathrm{Si}$, como señala Maturana, se niega la realidad objetiva independiente del observador y, como lo planteó en su "Ontología del observar", se reconoce al observador como un participante constitutivo de lo que observa, el cambio que aquí se propone es evidentemente radical: el paso de un Universo, es decir, de una realidad objetiva unívoca que es igual para todos, a un Multiverso, en que cada mundo construido por el observador es igualmente válido y único respecto de otros.

\section{La noción de lenguaje}

Otro de los aportes más extraordinarios de Humberto Maturana es su teoría del lenguaje. Para Maturana el lenguaje, como fenómeno de la vida, pertenece a la historia evolutiva de los seres humanos.

Son los humanos los primeros y únicos animales (primates, concretamente) que tienen la peculiaridad de vivir - en un fluir constante e ininterrumpido- una doble dimensión simultánea de experiencia: la primera es la experiencia inmediata (las emociones), que nos ocurre a todos los animales y según la cual algo simplemente pasa; la segunda, que ocurre solo al primate humano, es la explicación que tiene lugar en el lenguaje; solo en el lenguaje por ejemplo, se admite la existencia de categorías como lo bueno y lo malo, lo justo y lo injusto, que permiten comprender ese algo que pasa. Ahora bien, el lenguaje consiste en un operar recurrente de lo que Maturana denomina coordinaciones de coordinaciones conductuales consensuales.

Según ellas cada palabra o gesto no está relacionado con algo exterior a nosotros, sino con nuestro quehacer y con nuestra coordinación para ese quehacer con los otros. Son precisamente ese quehacer, y las emociones que están en su base, lo que específica y da a nuestras palabras su significado particular. Por esto, a nivel de la experiencia inmediata no se puede diferenciar lo que es una ilusión de una percepción; solo lo logramos en el lenguaje.

Y ya que sólo a través del lenguaje el ser humano puede explicar su experiencia en el vivir y asimilarla a la continuidad de su praxis de vida, el comprender es inseparable de la experiencia humana: todo el reordenamiento racional cognitivo que pueda elaborarse se basa, en premisas tácitas que han sido proporcionadas por la experiencia inmediata. En palabras de Maturana: "Todo sistema racional tiene una base emocional y esto explica por qué no se puede convencer a nadie con un argumento lógico si no se ha aceptado antes su 
premisa a priori". Desde el punto de vista de la psicoterapia, este planteamiento es una alternativa a los enfoques racionalistas que postulan que mediante el ejercicio de la lógica formal es posible cambiar las emociones del paciente.

Pero, además, Maturana va más allá y acuña el término lenguajear, con el que denomina a la relación dinámica y funcional que se da entre la experiencia inmediata y la coordinación de acciones consensuales con los otros y aclara que este lenguajear está constituido por la relación entre las emociones y el lenguaje.

Esta concepción revierte el enfoque empirista clásico que ve al lenguaje como simple transmisión de información de un individuo a otro, postura que tan vigente que no se prevé un cambio ni en la próxima década. En este sentido, la propuesta de Maturana -con su significado emocional y no racional- tendrá que ser reconocida como la teoría más explicativa. En su enfoque ontológico el lenguajear corresponde a una expresión de la temporalidad humana: todo lo que ocurre, ocurre en el lenguaje, en el aquí y en el ahora.

\section{La concepción de cultura}

Para Humberto Maturana la experiencia humana tiene lugar en el espacio relacional del conversar. Esto significa que si bien desde un punto de vista biológico somos homo sapiens, nuestro modo de vivir -vale decir, nuestra condición humana- tiene lugar en nuestra manera de relacionarnos unos con otros y con el mundo que configuramos en nuestro diario vivir mediante el conversar.

Sostiene que una cultura es una red cerrada de conversaciones y que el cambio cultural ocurre cuando se produce un cambio de conversaciones en esa red; cambio que surge, se sostiene y se mantiene en el emocionar de los miembros de la comunidad. De ello se desprende que lo humano es cultural: surge como un modo de vivir en el conversar, en redes de conversaciones, en un entrelazamiento entre el lenguajear y el emocionar. Esto significa, siguiendo a Maturana, que toda la experiencia humana se da en el momento presente; no existe una programación anterior ni obedece tampoco a intenciones.

Aún más, tampoco en el proceso de la evolución, sea este biológico o cultural, existe un camino preestablecido. El devenir evolutivo es una deriva, en tanto que el presente evolutivo humano es resultado de un proceso que conserva una manera de vivir y no un logro de proceso de adaptación. 


\section{La Biología del Amor}

Maturana es el primer científico que desde su hacer como tal explica el amor. En su propuesta, el amor no es una cualidad o un don, sino que como fenómeno relacional biológico, consiste en las conductas o la clase de conductas a través de las cuales el otro, o lo otro, surge como un legítimo otro en la cercanía de la convivencia, en circunstancias en que el otro, o lo otro, puede ser uno mismo. Esto, entendiéndose que la legitimidad del otro se constituye en conductas u operaciones que respetan y aceptan su existencia como es, sin esfuerzo, y como un fenómeno del mero convivir. Legitimidad del otro y respeto por él o ella, son dos modos de relación congruentes y complementarios que se implican recíprocamente. El amor es un fenómeno biológico propio del ámbito relacional animal, que en los mamíferos aparece como un aspecto central de la convivencia en la intimidad de la relación materno-infantil en total aceptación corporal. De acuerdo a Maturana, nos enfermamos al vivir un modo de vida que niega sistemáticamente el amor. 